\title{
The Significance of Ventricular Interdependence in Patients with Right Ventricular Hypertrophy and Normal Left Ventricular Function
}

\author{
NICOLAE PAUN ${ }^{1}$, IOAN TIBERIU NANEA ${ }^{1}$, CAMELIA NICOLAE' ${ }^{1}$, ALICE MUNTEANU ${ }^{2}$, FLORENTINA CRISTINA PLESA ${ }^{2}$, \\ MAGDALENA DIACONU ${ }^{3}$, ALINA BISOC ${ }^{4}$, MONICA MARILENA TANTU5 ${ }^{5}$, ELENA IOANA ICONARU5, ALINA PAUNESCU5*, \\ CONSTANTIN CIUCUREL ${ }^{5}$ \\ ${ }^{1}$ Carol Davila University of Medicine and Pharmacy, 8 Eroii Sanitari Blvd., 050474, Bucharest, Romania \\ ${ }^{2}$ Titu Maiorescu University of Bucharest, Faculty of Medicine, 22 Dambovnicului Str., 040441, Bucharest, Romania \\ 3 University of Medicine and Pharmacy Craiova, 2 Petru Rares Str., 200349, Craiova, Romania \\ ${ }^{4}$ Transilvania University of Brasov, Faculty of Medicine, 29 Eroilor Blvd., 500036, Brasov, Romania \\ ${ }^{5}$ University of Pitesti, Faculty of Sciences, Physical Education and Informatics, 1 Targu din Vale Str., 110040, Pitesti, Romania
}

\begin{abstract}
The aim of the study is to quantify ventricular interactions by comparing tissue and spectral systolic echocardiographic parameters to allow the early identification of ventricular dysfunction. Clinical, paraclinical, electrocardiographic and echocardiographic evaluations were performed. Right ventricular hypertrophy was diagnosed in the M mode subcostal echocardiographic section. RV hypertrophy was defined by a right ventricular free wall thickness of $>5 \mathrm{~mm}$ in diastole. We assessed the following RV and LV tissue and spectral systolic indices: apical systolic excursion of the lateral mitral ring (MAPSE), apical systolic excursion of the lateral tricuspid ring (TAPSE), left(Svs) and right(Svd) ventriculartissue systolic velocities, and RV and LV ejection times. We calculated the following to assess systolic ventricular interdependence: MAPSE/ TAPSE, the normal value of which was considered as $0.66 \pm 0.14$, and SvS/Svd, the normal value of which was considered as $0.76 \pm 0.21$. The study group was compared to a control group with the same clinical features but without ventricular hypertrophy. Twenty-one patients were included in the study: 13 men (62\%) and eight women (38\%) with a mean age of $56 \pm 3.8$ years. We compared the values between the study group and control group, with the following results: TAPSE $=20.4 \pm 0.9$ vs. $24.1 \pm 0.76$ and MAPSE/TAPSE $=0.74 \pm 0.06$ vs. $0.75 \pm 0.04$. MAPSE was comparable between the groups. Svs was comparable between the groups ( $0.09 \pm 0.01$ vs. $0.12 \pm 0.02)$, whereas Svd was different between the groups ( $0.11 \pm 0.03$ vs 0.16 \pm 0.03 ). Svs/Svd was $0.81 \pm 0.05$ in the study group and $0.75 \pm 0.08$ in the control group. LV ejection time was comparable between the two groups (299.8 $\pm 23.6 \mathrm{~ms}$ vs. $303.3 \pm 28 \mathrm{~ms})$, whereas, RV ejection time differed between the groups ( $275 \pm 17$ ms vs. $245.5 \pm 28.5)$. Changes in TAPSE and MAPSE/TAPSE, in addition to Svd and Svs/Svd, are related to right ventricular dysfunction and suggest pathological changes in the interdependence mechanism of the ventricles in patients with RV hypertrophy. In addition, RV free wall thickness was strongly correlated with ventricular interdependence parameters, with the exception of MAPSE. Assessing these parameters and proportions in clinical practice will facilitate the early detection and appropriate treatment of right ventricular dysfunction.
\end{abstract}

Keywords: interdependence, ventricular hypertrophy, MAPSE, TAPSE, systolic tissue velocities

Ventricular interdependence is the mechanism through which the size, shape, compliance, and pressure-volume curve of one ventricle can affect those of the other ventricle $[1,2]$. The main anatomical structures that enable ventricular interactions are the interventricular septum, pericardium, myocardial muscular fibers, which connect the two ventricles, and pulmonary vascular system $[3,4]$. The myocardial fibers of the right ventricle resemble a web composed of three layers and the main muscular components reside in the superficial and deep layers. In the superficial layer, the fibers are arranged predominantly in a circumferential orientation, parallel to the atrioventricular notch and oblique with respect to the cardiac apex, from where they continue within the superficial layer of the left ventricle. The longitudinal fibers in the right ventricular muscle are found in the deep layer. The existence and orientation of these muscular fibers, particularly the circumferential fibers, provide anatomical and functional connections between the two ventricles and contribute to the phenomenon known as ventricular interdependence [1.5]. Through this mechanism, the interaction facilitates traction of the free wall of the right ventricle with right ventricle contraction.
Pulmonary vascularization is one form of connection between the ventricles. Changes in the relaxation and/or contraction properties of the left ventricle lead to changes in the after-load of the right ventricle, with a subsequent impact on the function of the right ventricle [4]. Ventricular interdependence occurs continuously and is prominent in both postural and respiratory conditions. Furthermore, ventricular interdependence functions in both systole and diastole.

Diastolic ventricular interdependence has been demonstrated in laboratory experiments and clinical studies [6-13]. The interventricular septum moving towards the left ventricle after acute expansion of the right ventricle is one example of this phenomenon. This results in a decrease in the pre-load of the left ventricle, expansibility, and left ventricular output $[8,9,14]$. A previous report demonstrated that $20-40 \%$ of right ventricle systolic pressure is the result of contraction of the left ventricle [1].

Systolic ventricular interdependence is mainly provided by the interventricular septum. Evidence shows [6] that the presence of a scar in the free wall of the right ventricle or its replacement with a patch of non-contractile material does not have negative hemodynamic effects when the 
right ventricle is not dilated. Thus, the mechanism of ventricular interdependence is essential in both normal and pathological conditions [11,15-18]. The mechanism of ventricular interdependence reflects the equilibrium between the two ventricles. As such, the performance of the ventricles should be evaluated independently to describe the correct functioning of the mechanism.

In clinical practice, transthoracic echography is a reliable and accessible method of verifying ventricular interdependence. This method allows systolic ventricular parameters to be assessed [19]. A previous study [20] used the relative proportion of systolic apical excursion of the mitral ring (MAPSE) to systolic ventricular excursion of the lateral tricuspid ring (TAPSE) as a measure of interdependence. The value of MAPSE/TAPSE in healthy people is $0.66 \pm 0.14$. The same authors proposed a second marker of ventricular interdependence: the relative proportion of tissue systolic velocity of the left ventricle (Svs) to tissue systolic velocity of the right ventricle (Svd). The normal value of Svs/Svd is $0.76 \pm 0.21$. These two values are calculated without taking into consideration differences in sex, age, or body area. The use of these proportions in clinical practice could enable the evaluation of ventricular interdependence.

\section{Experimental part}

This study aimed to evaluate the mechanism of ventricular interdependence in clinical practice by comparing the systolic parameters of both ventricles in patients with right ventricular hypertrophy and normal left ventricular function.

The studied cohort was composed of patients with an echographically-determined diagnosis of right ventricular hypertrophy. The exclusion criteria were as follows: heart failure, essential arterial hypertension grade II and III with additional high and very high risks [21,22], severe and moderate valvulopathies, primary and/or secondary diseases of the cardiac muscle, diseases of conduction and/or rhythm, pericarditis, primitive pulmonary hypertension, moderate or severe secondary pulmonary hypertension [23,24], ischemic coronary disease, different infections [25-27], different lesions, such as diabetic foot $[28,29]$ and oncologic diseases [30-34].

Research approaches have respected the ethical and deontological norms in research and the protection of personal data [35,36].

The patients were evaluated clinically and para-clinically. The diagnosis of right ventricular hypertrophy was made with cardiac echography using the subcostal section with the image amplified by measuring thickness of the free wall of the right ventricle. Right ventricle hypertrophy was defined as a thickness $\geq 5 \mathrm{~mm}$ in diastole.

The echocardiographic parameters used in the study were MAPSE, TAPSE, Svd, Svs, MAPSE/TAPSE, Svs/Svd, and left and right ventricular ejection times.

MAPSE was obtained in the lateral apical four-chamber view in M mode, whereas TAPSE was obtained from the same apical section in the lateral part of the tricuspid ring. The normal values were $>12 \mathrm{~mm}$ and $20 \mathrm{~mm}$, respectively.

Ejection time was obtained for the left ventricle in the apical section by applying the sample volume for spectral Doppler at the ejection tract, proximal to the aortic valves, and measuring the time of aortic systole. Right ventricular ejection time was obtained from the sagittal section by putting the sample volume at the ejection tract of the right ventricle, proximal to the pulmonary valves, and measuring the time of pulmonary systole $[19,37]$.

Svs was determined as the mean of the lateral and medial systolic tissue values. These were obtained in the apical section by placing a sample tissue Doppler volume at the lateral and medial mitral ring. Svd was obtained from the apical section by placing the sample volume at the lateral tricuspid ring. The normal values for Svs and Svd were taken as $>0.09 \mathrm{~cm} / \mathrm{sec}$ and $>0.10 \mathrm{~cm} / \mathrm{sec}$, respectively.

For statistical analysis, we compared quantitative data using the chi-square test and Student's t-test. Statistical significance was set at $p \leq 0.05$ (with a $95 \%$ confidence interval). For establishing statistical correlations between the parameters, we used Pearson's correlation analysis. The data were described as means \pm standard deviations for continuous variables and as percentages for categorical variables.

\section{Results and discussions}

Twenty-one patients were included in the study: 13(62\%) men and eight women (38\%). The age range was 48-74 and the mean age was $56 \pm 3.2$ years. The study group was compared with a control cohort, which included people with the same basic characteristics as those in the study group but without right ventricular hypertrophy.

The clinical characteristics of the study group were comparable to those of the control group (tables 1).

There was a difference in mean age between the study group ( $56 \pm 3.2$ years) and control group ( $63.5 \pm 3.7$ years). Furthermore, the incidence of smoking in the study group was greater than that in the control group: $81 \%$ vs. $31 \%$, respectively. The incidence of diabetes mellitus, dyslipidemia, and arterial hypertension was the same in the two groups.

Taking into consideration the echocardiographic parameters assessed in the study, the free wall of the right ventricle was thicker in the study group $(11.4 \pm 1.9 \mathrm{~mm})$ than in the control group ( $5.25 \pm 0.9 \mathrm{~mm}$ ) (table 2a).

As shown in Table 2a, there were significant differences in right ventricle free wall, TAPSE, and MAPSE/TAPSE between the study group and control group. Svs was compatible between the groups, whereas Svd different between the groups. Svs/Svd differed between the study group $(0.81 \pm 0.05)$ and control group $(0.75 \pm 0.08)$. The ejection time of the left ventricle was comparable between the two cohorts ( $299.8 \pm 23.6 \mathrm{~ms}$ vs. $303.3 \pm 28 \mathrm{~ms}$ ) but different for the right ventricle ( $275 \pm 17 \mathrm{~ms}$ vs. $245.5 \pm$ 28.5 (table 2b).

Table 1

THE CLINICAL CHARACTERISTICS OF THE STUDY GROUP AND CONTROL GROUP

\begin{tabular}{|l|c|c|c|}
\hline & Study Group & Control Group & Statistically significant \\
\hline Mean age (years) & $56 \pm 3.2$ & $63.5 \pm 3.7$ & Yes \\
\hline Patients & $21(13 / 8)$ & $16(9 / 7)$ & No \\
\hline Diabetes & $3(14 \%)$ & $2(12 \%)$ & No \\
\hline Dyslipidemia & $3(14 \%)$ & $2(12 \%)$ & Yes \\
\hline Smoking & $17(80 \%)$ & $7(31 \%)$ & No \\
\hline Hypertension & $6(28 \%)$ & $4(25 \%)$ & REV.CHIM.(Bucharest) 70 No. 10 \\
\hline
\end{tabular}


Table 2a

ECHOCARDIOGRAPHIC PARAMETERS IN THE STUDY GROUP AND CONTROL GROUP

\begin{tabular}{|c|c|c|c|}
\hline & Study Group & Control Group & Statistically significant \\
\hline $\begin{array}{l}\text { Right ventricle } \\
\text { free wall thickness }(\mathrm{mm})\end{array}$ & $11.4 \pm 1.9$ & $5.25=0.9$ & Yes \\
\hline $\begin{array}{l}\text { MAPSE } \\
(\mathrm{mm})\end{array}$ & $15.1 \pm 0.1$ & $15.6 \pm 0.82$ & No \\
\hline $\begin{array}{ll} & \text { TAPSE } \\
(\mathrm{mm}) & \end{array}$ & $20.4 \pm 0.9$ & $24.1 \pm 0.76$ & Yes \\
\hline MAPSE/TAPSE & $0.74 \pm 0.06$ & $0.65 \pm 0.04$ & Yes \\
\hline
\end{tabular}

MAPSE = systolic apical excursion of the mitral ring, TAPSE = systolic ventricular excursion of the lateral tricuspid ring.

Table $2 b$

THE RESULTS OF THE ECHOCARDIOGRAPHIC PARAMETERS IN THE STUDY GROUP AND CONTROL GROUP

\begin{tabular}{|l|c|c|c|}
\hline & Study Group & Control Group & $\begin{array}{c}\text { Statistical } \\
\text { significance }\end{array}$ \\
\hline Svd & $0.11 \pm 0.03$ & $0.16 \pm 0.03$ & Significant \\
\hline Svs & $0.09 \pm 0.01$ & $0.12 \pm 0.02$ & Nonsignificant \\
\hline Svs/Svd & $0.81 \pm 0.05$ & $0.75 \pm 0.08$ & Significant \\
\hline $\begin{array}{l}\text { LV ejection time } \\
\text { (S1) }\end{array}$ & $299.87 \pm 23.62$ & $303.31 \pm 28.02$ & Nonsignificant \\
\hline $\begin{array}{l}\text { RV ejection time } \\
\text { (S2) }\end{array}$ & $275 \pm 17.04$ & & Significant \\
& & $245.5 \pm 28.53$ & \\
\hline
\end{tabular}

Svs = tissue systolic velocity of the left ventricle; Svd = tissue systolic velocity of the right ventricle; LV = left

ventricle; $R V=$ right ventricle.

Figures 1 and 2 show examples of reduced TAPSE in a patient with right ventricle hypertrophy in the four-chamber view.

Through statistical analysis, we detected correlations between the thickness of the free wall of the right ventricle and the systolic parameters of both ventricles. The thickness of the free wall of the right ventricle in the study group was weakly correlated with left ventricular ejection time $(r=0.352)$. Strong positive correlations were detected between the thickness of the ventricular wall and TAPSE ( $r$ $=0.590)$, MAPSE $/ T A P S E(r=0.634)$, Svd $(r=0.634)$, Svs $(r$ $=0.532)$, and Svs/Svd $(r=0.606)$.

Bruhl et al. [20] established the normal value of MAPSE/ TAPSE as $0.66 \pm 0.14$ and that of Svs/Svd as $0.76 \pm 0.19$. This previous study was performed in healthy volunteered and established that these values are independent of age, sex, or body area. The present study used these previously

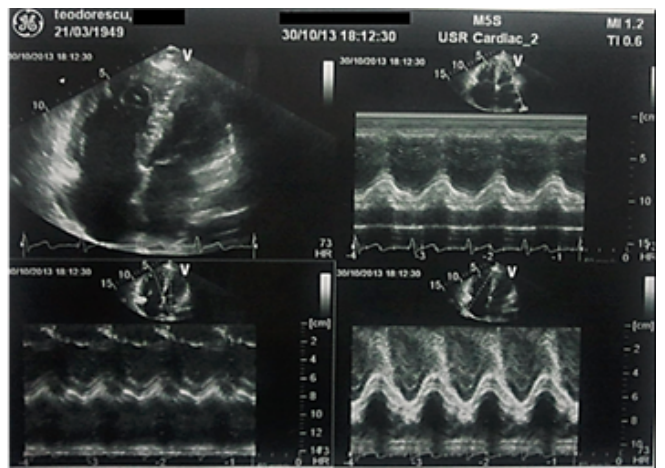

Fig. I. Two-dimensional apical section (upper left) showing hypertrophy of the free wall of the right ventricle associated with apical systolic excursion at the lower limits of the normal range at the tricuspid ring (lower right). The echographic image of the lateral mitral ring (upper right) and medial (lower left) shows normal systolic levels of movement.

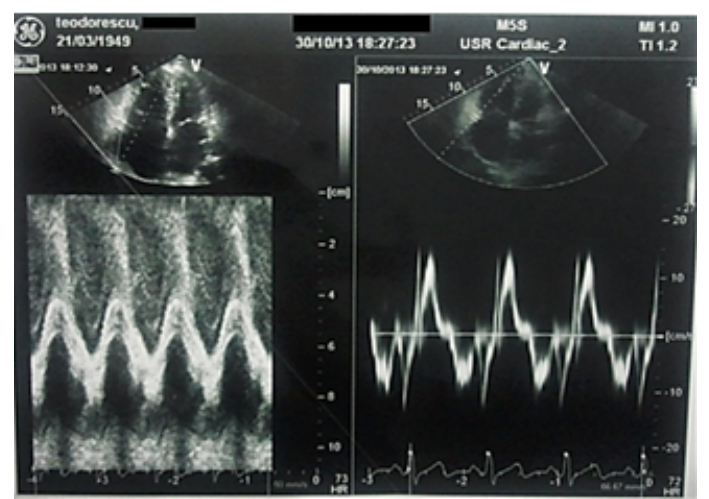

Fig. 2. Spectral Doppler ultrasound (left) and tissue (right) readings of the lateral tricuspid ring highlighting systolic velocities at the lower limits of the normal range

determined values to assess ventricular interdependence in patients with right ventricular hypertrophy and normal left ventricular function.

In this study, the mean age was lower in the study group than that in the control group. This finding, combined with the higher frequency of smoking in the study group (80\%) vs. the control group (31\%), could explain the increase in right ventricle free wall thickness observed in the study group. These patients had obstructive chronic pulmonary disease, leading to an increase in right ventricle after-load with obvious consequences on the development of hypertrophy.

In the study group, right ventricle hypertrophy was associated with reduced TAPSE compared to the value observed in the control group. In the study group, TAPSE was at the lower end of the normal range, without reaching pathological levels. Svd and TAPSE were lower in the study 


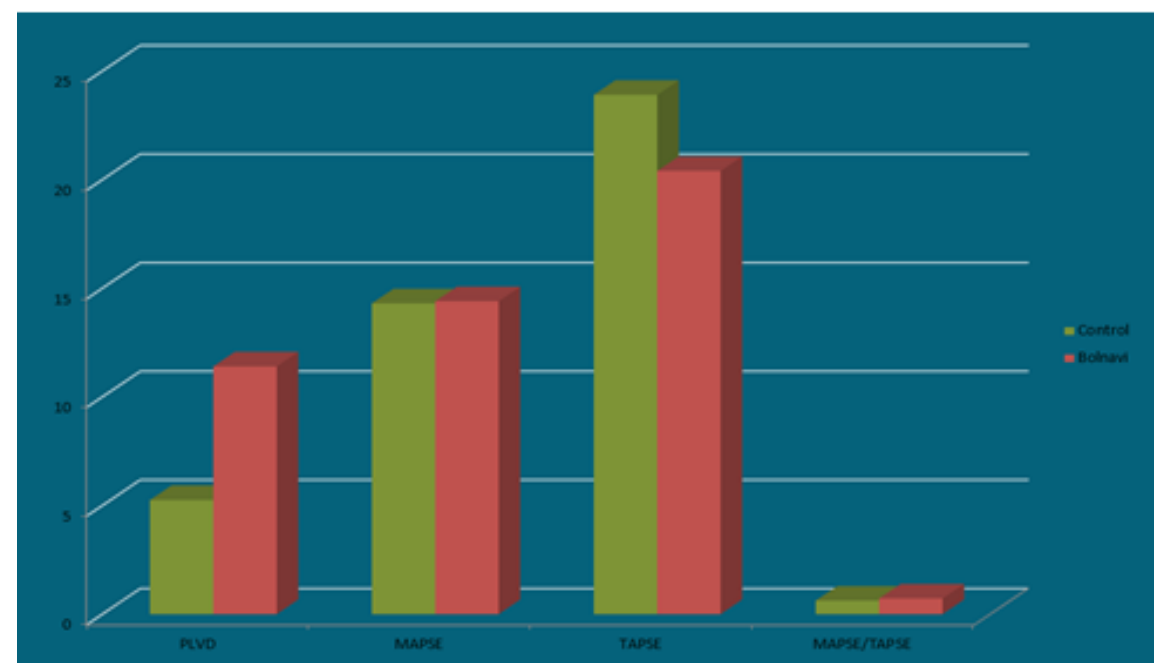

Fig. 3. Comparison of echocardiographic parameters. PLVD $=$ free wall of the right ventricle; MAPSE = apical excursion of the lateral mitral ring; TAPSE = apical excursion of the lateral tricuspid ring

group than in the control group, possibly due to the decrease in the contractile properties of the hypertrophied myocardial fibers. The values of Svd were higher than those of Svs in this study, and were considered to be within the normal range. These findings are also supported by the previous literature. This phenomenon is explained by decreased vascular resistance of the pulmonary arterial vessels, although the muscular mass of the right ventricle showed a more severe reduction than that of the left ventricle.

The longitudinal function of the left ventricle described by MAPSE was comparable between the two groups and fell within the normal range $(15.1 \pm 0.01$ vs. $15.6 \pm 0.82)$ (figure 3).

MAPSE/TAPSE were higher in the study group than in the control group. The pathological significance of this parameter suggests that the interdependence mechanism is altered by changes in the function of the right ventricle. The same concept is suggested by the pathological change observed in Svs/Svd $(0.81 \pm 0.5$ vs. $0.75 \pm 0.08$ for the study and control groups, respectively). We also observed a statistically significantincrease in right ventricle ejection time in the studied patients.

Understanding the mechanism and consequences of ventricular interdependence has been the aim of numerous clinical and experimental studies. Of these, many $[7,8,10,11,17,18,38]$ have aimed to explain the phenomenon from the perspective of systolic function. Santamore and Burkhoff [9] published a study that described the way in which ventricular interdependence influences flow variations after separate unilateral changes in ventricular after-load and contractility. They used an electric circuit to simulate cardiovascular apparatus, in which they placed diodes corresponding to arterial and venous resistance, impedance, venous and arterial compliance, and myocardial elasticity. The team proposed novel mathematical formulae to predict changes in the pressure-volume relationship for each ventricle in the presence and absence of ventricular interdependence. By blocking or unblocking each element in these circuits, the authors revealed importantmechanisms behind ventricular interdependence. By augmenting vascular resistance, interdependence leads to a decrease in systolic flow. By increasing pulmonary vascular resistance, ventricular interdependence determines, in contrast to the reaction of the left ventricle, a more severe decrease of right systolic flow, a phenomenon that is not present in the absence of ventricular interdependence.

A previous study highlighted the importance of ventricular interdependence in a number of artificially induced right ventricular conditions. Moulopoulos etal. [10] performed by-pass on the right heart, in which pulmonary artery pressure was increased by interrupting the filling and dilating of the right ventricle. In every phase of the experiment, the compliance, filling, and after-load of the left ventricle were maintained at constant levels with the aim of excluding their influence on systemic hemodynamics. Through this experiment, the authors revealed that the decrease in the proportion between the pressure unit per time unit (dp/dt) during by-pass and the increase in the distension of the right ventricle could reflect a decrease in the contractility of the left ventricle. This previous study demonstrated the positive influence of the normal function of the right ventricle on the function of the left ventricle and the anatomical connection between the two ventricles.

Slinker et al. [8] performed a study in the context of left ventricular hypertrophy to reveal the role of direct interdependence through the interventricular septum and, indirectly, in series through the pulmonary circulation. The experiment involved applying different statistical models to analyze the behavior of the pressure and dimensions of the left and rightventricles after occlusion of the vena cava and pulmonary artery. The authors found that at the end of diastole, the direct interaction through the interventricular septum represented just 10\% of the indirect interaction through the pulmonary circulation and that at the end of systole, direct interdependence represented $20 \%$ of the indirect interdependence. After the removal of the pericardium, the influence of direct ventricular interdependence was diminished. The authors concluded that hypertrophy caused by supra-load decreased ventricular interactions. Furthermore, Santamore show ed that hypertrophy induces pronounced increases in the interventricular septum compared to the free wall, which results in reduced extensibility of the septum. The conclusion in both experiments was that hypertrophy, by decreasing myocardial elasticity, complicates the analysis of the pressure-volume relationship between the two ventricles.

Nunez [16] also revealed similar findings in a clinical study in hypertensive patients and normotensive patients. The study analyzed the behavior of the left ventricle and revealed a two-fold increase in the thickness of the right ventricle muscle in the presence of left ventricular hypertrophy in hypertensive patients. The mechanism for this could be reduced ventricular interactions followed by an initial reduction in the performance of the right ventricle, followed by a compensatory increase in its contractility and subsequent hypertrophy. 
In the present study, tissue systolic velocity (S2) of the free wall of the right ventricle and TAPSE were higher than the tissue velocity (S1) of the left ventricle and MAPSE and lower than the normal values, which could suggest the early onset of systolic dysfunction of the right ventricle. MAPSE/TAPSE and Svs/Svd presented pathological values of $0.072 \pm 0.6$ and $0.81 \pm 0.07$, respectively. These values suggest the alteration of the ventricular interaction mechanism caused by the settlement, in the incipient subclinical phase, of systolic dysfunction of the right ventricle. From the statistical perspective, the right ventricular free wall thickness was significantly positively correlated with ventricular interdependence parameters. However, we could not determine whether there was a causal relationship. Strong positive correlations were also detected between right ventricular free wall thickness and the tissue systolic velocity of both ventricles (also without a causal relationship).

One limitation of this study was the small number of patients, which limited the ability to perform rigorous statistical analysis of the results.

\section{Conclusions}

Transthoracic echocardiography of tissue and spectral Doppler parameters allows the evaluation of systolic ventricular interdependence in clinical practice. In patients with right ventricular hypertrophy and normal systolic function of the left ventricle, changes in TAPSE and MAPSE/ TAPSE, in addition to Svd and Svs/Svd, appear to be related to right ventricular dysfunction and suggest pathological changes in the ventricular interdependence mechanism. In addition, right ventricular free wall thickness is strongly correlated with ventricular interdependence parameters, with the exception of MAPSE. Assessing these parameters and proportions in clinical practice could allow the early detection and timely treatment of right ventricular dysfunction, improving the function of the right ventricle and patient outcomes and quality of life.

\section{References}

1.HADDAD,F., HUNT, SA., ROSENTHAL,DN., MURPHY, DJ ., Circulation, 2008, 117, p:1436-1448

2.HADDAD, F., DOYLE, R., MURPHY, DJ ., HUNT, SA., Circulation, 2008, 117, $\mathrm{p}: 1717-1723$

3.KAWUT, SM., GRAHAM-BARR, R., LIMA, AC., PRAESTGAARD, A., CRAIG-J OHNSOHN, W., CHAHAL, H., OGUNYANKIN, K., BRISTOW, MR., KIZER, JR., TANDRI, H., BLUEMK, DA., Circulatio, 2012, 126(4), p:16811688

4. AGOSTON-COLDEA, L., LUPU, S., PETROVAI, D., MOCAN, T., MOUSSEAUX, E., Med Ultrason, 2015, 17(4), p:487-495

5.GUPTA, S., KHAN, F., SHAPIRO, M., WEEKS,SG., LITVIN, SE., MICHAELS, AD., European J ournal of Echocardiography, 2008, 9, p:766771

6.PINSKY MR., Critical Care, 2016, 20, p:266

7.BUCKBERG G., NANDA, NC., COGHLAN, C., SALEH S., Echocardiography, 2011, 28, p:782-804

8.SLINKER, BK., CHAGAS, AC., GLANTZ, SA., American Journal of Physiology 1987; 253, p:H347-57

9.SANTAMORE, WP., BURKHOFF, D., American J ournal of Physiology 1991; 29, p:H146-H157

10.MOULOPOULOS, SD., SARCAS, A., STAMATELOPOULOS, S., AREALIS, E., Circulation Research 1965; XVIII, p:484-494

11.NAEIJE, R, BADAGLIACCA, R., Cardiovascular Research. 2017, 113(12), p:1474-1485.
12.SECKELER, M., WHITE, S., WEST, S., SAUNDERS, C., JAYAKUMAR, K., Journal of American College of Cardiology 2012; 59, p:E1150 13.ALIZADEHAS, A., SADEGHPOUR, A., HALI, R., BAKSHHANDEH ABKENAR, H., BADANO, L., Ecocardiography. 2017; 34(3), p:415-421 14.BUCKBERG, G., HOFFMANN, IE., The Journal of Thoracic and Cardiovascular Surgery. 2014; 148, p:3166-71

15.SEKINE, I., TAKAHASI, M., MURATA, M., KIRA, Y., OKABE, F., ITO, T., Japanese Circulation Journal. 1989; 53, p:1245-52

16.NUNEZ, BD., MESSERLI, FH., AMODEO, C., GARAVAGLIA, GE., SCHMIEDER, RE., FROHLICH, ED., American Heart] ournal. 1987; 114, $\mathrm{p}: 813-8$

17.HARDEGREE, E., VILLARRAGA, H., N.AMMASH, N. et al., Chest Journal, 2011, 140(4), Supplement, p:745A

18.DRIESSEN, MMP., HUI, W., BIJ NENS, BH. et al., Physiol Rep. 2016; 4(11), p:e12833.

19.LINDQUIST, P., CALCUTEEA, A., HENEIN, M., European Journal of Echocardiography 2008; 9, p:225-234

20.BRUHL, SR., CHAHAL, M., KHOURI, SJ ., Cardiovascular Ultrasound. 2011; 9, p:42

21.TANTU M, BELU E., BOBESCU E., et al., FARMACIA, 2014, Vol. 62, 3, p:451-459

22.PLESA CF, NICOLAE C, SIRBU CA, NEMES R, PAUNESCU A, TANU MM, FARMACIA, 2019, Vol. 67, 1, p:27-33

23.IANOSI, E.S., POSTOLACHE,. P., MACOVEI, L.A, SZATHMARY, M., SZASZ, S., NEMES, R.M., JIMBOREAN, G., Rev.Chim. (Bucharest), 69, 2018, p.1766-1769.

24.POSTOLACHE P, NEMES RM, PETRESCU 0, et al., Medical-Surgical Journal 2015; 119, p:77-80.

25.TANTU, M.M., MAN, G.M., PAUNESCU, A.,. et al., Rev.Chim. (Bucharest), 69, no. 11, 2018, p.3001-3005

26.DUCEAC, L.D., TARCA, E., CIUHODARU, M.I., TANTU, M.M. et al., Rev. Chim. (Bucharest), 70, no. 1, 2019, p: 199-201

27.NITU, FM, OLTEANU M, STREBA CT, etal., Rom J Morphol Embryol, 2017; 58, p:385-392.

28.TANTU, MM., MAN, G.M., ROGOZEA, L.M. et al., Rom J Morphol EMBRYOL 2018, 59(3), p:895-902

29.TANTU, M.M., MAN, G.M., PAUNESCU, A. et al., Rev. Chim. (Bucharest), 70, no. 4, 2019, p:1307-1310

30.DIACONESCU, DE., DIMA, L., MARINESCU, DM., TANTU, MM., ROGOZEA, LM., Rom J Morphol Embryol 2014, 55(4), p:1371-1375

31.AVRAMOIU I, PETRESCU IO, CIUREA ME et al., Rom J Morphol Embryol, 2016; 57(3), p:943-950

32.IORDACHE PD, MATES D, NICOLAE C et.al., J Cell Mol Med. 2018; 22, p:6068-6076.

33.STEFANESCU, D.C, CEACHIR, O., ZAINEA, V., HAINAROSIE, M., PIETROSANU, C., IONITA, I.G., HAINAROSIE, R., Rev. Chim. (Bucharest), 67, 2016, p. 1327-1328

34.STEFANESCU DC, CEACHIR 0, ZAINEA V, HAINAROSIE M, PIETROSANU, C, IONITA IG, HAINAROSIE R, Rev. Chim. (Bucharest), 67, 2016; p:1255-1256

35.CONSTANTIN, D.A., CIORICEANU, I.H., TÂNTU, M.M., POPA, D., BÃDÃU, D., BURTEA, V., NEMET, G.C, ROGOZEA, L.M., Rom J Morphol Embryol, 2017, 58(3), p:1121-1125.

36.POPESCU IG, SECHEL G, LEASU FG, TANTU MM, COTOI GG, ROGOZEA LM, Rom J Morphol Embryol 2018; 59(3), p:1001-1005

37.*** AMERICAN SOCIETY OF ECHOCARDIOGRAPHY AND THE EUROPEAN ASSSOCIATION OF CARDIOVASCULAR IMAGING: Recomandation for Cardiac Chamber Quantification by Echocardiography in Adults 2015. Journal of American Society of Echocardiography 2015; 28, p:1-39

38.AMOORE, JN., SANTAMORE, WP., CORIN, WJ., GEORGE, DT., Journal of Biomedical Engineering 1992; 14, p:257-262

$\overline{\text { Manuscript received: } 23.09 .2019}$ 